\title{
LA ÉTICA Y LA PRÁCTICA POLÍTICA: REPENSANDO LOS USOS DEL CONCEPTO DE HEGEMONIA Y EVENTO EN LAS ELECCIONES BRASILEÑAS DE 2002
}

\author{
A ÉTICA E A PRÁTICA POLÍTICA: REPENSANDO OS USOS DO CONCEITO DE \\ HEGEMONIA E ACONTECIMENTO NAS ELEIÇÕES DE 2002
}

\section{ETHICS AND POLITICAL PRACTICE: RETHINKING THE USES OF THE CONCEPT OF HEGEMONY AND EVENT IN THE 2002 BRAZILIAN GENERAL ELECTION}

\author{
L'ÉTHIQUE ET LA PRATIQUE POLITIQUE : LES USAGES DU CONCEPT \\ D'HÉGÉMONIE ET D'ÉVÉNEMENT LORS DES ÉLECTIONS BRÉSILIENNES DE 2002
}

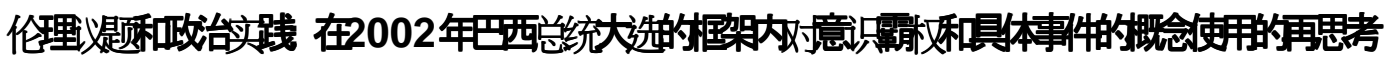

DOI: $10.5533 / 1984-2503-20135203$

Daniella Amaral Diniz da Silva ${ }^{1}$

\section{RESUMEN}

En este trabajo pretendo problematizar la idea de la ética en relación con la teoría y práctica de los discursos de la llamada izquierda que asumen importancia dentro de los movimientos sociales latinoamericanos, con énfasis en el caso brasileño. Como fondo teórico investigamos cómo las categorías de hegemonía, propuesta por Ernesto Laclau y de evento, desarrollada por Alain Badiou extrapolan sus límites teóricos cuando son pensadas desde la práctica política. Partiendo de un caso real, la elección a la presidencia de Luis Inácio Lula da Silva como icono y figura destacada del partido de los trabajadores (PT), pretendo analizar de qué manera el ejercicio del poder se mezcla con una determinada concepción de ética para construir un discurso político y qué estrategias se utilizan en estos campos hegemónicos para encontrar legitimidad. El material para el análisis en cuestión constituye principalmente la película documental de João Moreira Salles (Entreactos), y algunos materiales suplementarios.

\footnotetext{
${ }^{1}$ Bacharel em Ciências Sociais pela Universidade Federal do Rio de Janeiro (2005), mestre em História pela Universidade Federal Fluminense (2008), e em Estudos Latino-Americanos e Ibéricos pela Universidade de Columbia em Nova lorque (2010). Atualmente, é doutoranda nesta mesma instituição, onde ensina cursos na área de língua e cultura brasileira. E-mail: $\underline{\text { dad2141@columbia.edu }}$
} 
Palabras clave: Teoria Política, Cinema, Elecciones, Lula, Populismo.

\section{RESUMO}

Neste trabalho pretendo problematizar a ideia de ética em relação com a teoria e a prática dos discursos da chamada esquerda que assumem importância nos movimentos sociais latino-americanos, com ênfase no caso brasileiro. Como fundo teórico, investigamos como as categorias de hegemonia, proposta por Ernesto Laclau e de evento, desenvolvida por Alain Badiou extrapolam seus limites teóricos quando são pensadas a partir da prática política. A partir de um caso real, a eleição para a presidência de Luis Inácio Lula da Silva como ícone e figura destacada do Partido dos Trabalhadores (PT), pretendo analisar de que maneira o exercício do poder se mistura com uma determinada concepção de ética para construir um discurso político e quais estratégias se utilizam nestes campos hegemônicos para encontrar legitimidade. O material para a análise em questão constitui principalmente o documentário de João Moreira Salles (Entreatos), e alguns materiais suplementares.

Palavras-chave: Teoria Política, Cinema, Eleições, Lula, Populismo.

\section{ABSTRACT}

In this article I investigate the idea of ethics in terms of the theory and practice of the discourse of the so-called left, to have assumed significance within the framework of Latin American social movements, with a particular emphasis on Brazil. This analysis provides theoretical basis on how the categories of hegemony, proposed by Ernesto Laclau, and event, developed by Alain Badiou, extrapolate their theoretical limits when considered in terms of political practice. Based on the real-life example of the election to the presidency of Luiz Inácio Lula da Silva, an icon and leading figure in the Workers' Party (PT), I emphasize how the exercise of power blends with a certain concept of ethics to construct political discourse, and which strategies are employed in these hegemonic fields in the search for legitimacy. The primary source of analysis in this work is the documentary film by João Moreira Salles (Entre-Atos), along with some other supplementary sources.

Key words: Political Theory, Cinema, Elections, Lula, Populism.

\section{RÉSUMÉ}


II s'agit dans cet article de problématiser l'idée d'éthique en relation avec la théorie et la pratique des discours de la gauche au sein des mouvements sociaux latino-américains, et ici plus particulièrement brésiliens. En toile de fond théorique, nous analyserons comment les notions d'hégémonie (proposée par Ernesto Laclau) et d'événement (développée par Alain Badiou) extrapolent leurs limites théoriques lorsqu'elles sont pensées sur la base de la pratique politique. À partir d'un cas concret, l'élection à la présidence de Luis Inácio Lula da Silva, icône et figure incontournable du Parti des travailleurs (PT), nous analyserons de quelle manière l'exercice du pouvoir incorpore une conception donnée de l'éthique pour construire un discours politique et quelles sont les stratégies utilisées dans ces champs hégémoniques pour conquérir sa légitimité. Le matériel analysé est principalement constitué du film documentaire Entreatos de João Moreira Salles et de quelques autres documents.

Mots-clés: Théorie politique, Cinéma, Élections, Lula, Populisme.

\section{提要}

本论文探讨政治实践中伦理议题在拉美社会运云打所谓左派的话语中所起的作用一

以巴西例。在政治学理伦的基㑁上探扵Ernesto Laclau 的主导意识 (hegemonia), 和Alain Badiou的具体事件(evento)，及其在政治实践上的挶限性。本论文以巴西工人党的领袖 工人党 的标志性人物鲁拉Luis Inácio Lula da Silva 在2002年总统大选中的选举话语和具体行为进行研究 试冬分析政治实践中，伦理议题和权力议题的结合而产生的政治话语，为了争夺合法性ＰT融合了主导意识 策划了新 的选举策略。主要资料来源于巴西的纪录片制作人João Moreira Salles 的作品“来龙去脉” (Entreatos) 和其他的补充材料。

关键司: 政治学理论 电影，大选 鲁拉，民众主义。

En este trabajo pretendo problematizar la idea de la ética en relación con la teoría y práctica de los discursos de la llamada izquierda que asumen importancia dentro de los movimientos sociales latinoamericanos, con énfasis en el caso brasileño. Como fondo teórico, me interesa investigar cómo las categorías de hegemonía, propuesta por Ernesto Laclau y de evento, desarrollada por Alain Badiou extrapolan sus límites teóricos cuando son pensadas desde la práctica política. Partiendo de un caso real, la elección a la presidencia de Luis Inácio Lula da Silva como icono y figura destacada del partido de los trabajadores (PT), pretendo analizar de qué manera el ejercicio del poder se mezcla con una determinada concepción de ética para construir un discurso político y qué estrategias 
se utilizan en estos campos hegemónicos para encontrar legitimidad. El material para el análisis en cuestión constituye principalmente la película documental de João Moreira Salles (Entreactos), y algunos materiales suplementarios ${ }^{2}$.

Tal y como lo formula Ernesto Laclau, la hegemonía se define por el "proceso por el cual una particularidad asume la representación de una universalidad con la que es en última instancia inconmensurable". 3

Efectivamente, Laclau pretende actualizar algunos conceptos clave del Marxismo, poniéndolos en diálogo con la práctica política contemporánea. Su propósito original es responder a la necesidad de construir una política de izquierda que pase por la afirmación de identidades nacionales y populares, superando el planteamiento estrictamente clasista que marcó el discurso del campo marxista más ortodoxo a partir de los años 60 . Partiendo de algunos principios del discurso tradicional marxista, su objetivo es expandir y relativizar la noción de totalidad histórica y de determinismo económico cómo referencias datadas teniendo en cuenta los límites de la categoría de clase en los análisis de las relaciones de poder. Para Laclau, la idea de que el conjunto de los hechos sociales tiene una estructura unificada, orgánica e inteligible, es un principio que debe ser puesto en duda y la idea de una 'determinación en última instancia' de lo económico no tiene sentido en la sociedad contemporánea, marcada por la multiplicidad y fragmentación de identidades, intereses y conflictos. De manera pragmática, lo que debe ser teorizado y desarrollado son conceptos y principios capaces no solamente de explicar lo real sin reducirlo o generalizarlo. Estos principios y categorías básicas, sin embargo, no dejan de cumplir con la ideología marxista, en la justa medida en que deben componer una agenda política orientada a cambios socioeconómicos que tengan a la vista las necesidades de los grupos históricamente desfavorecidos.

Entretanto, frente a este panorama no hay exclusivamente un solo propósito dentro del proceso histórico (lucha de clases), y la lucha ideológica que él piensa está marcada precisamente por la pluralidad de intereses, estrategias y esfuerzos de asumir una posición de preeminencia, o sea, una lucha de campos hegemónicos en disputa. Mediante esa universalidad fragmentada, la articulación - según Laclau - es lo que permite diferenciar e identificar estos distintos elementos de composición de los campos

\footnotetext{
${ }^{2}$ De campaña (como la "Carta al pueblo brasileño" firmada por el entonces candidato en Junio de 2002), entrevistas a Lula posteriores a su victoria y al largo de su ejercicio de las funciones de presidente dentro y fuera de Brasil.

${ }^{3}$ Laclau, Ernesto (2008). "Por una ética militante". In Debates y combates: por un nuevo horizonte de la política, Buenos Aires, Fondo de Cultura Económica, p. 79-80.
} 
hegemónicos. Es la articulación lo que permite estratégicamente negociar y vencer las disputas en juego. La articulación política es lo que establece principios de relación entre campos hegemónicos desde el punto de vista práctico, y lo que incide sobre estos campos con el fin de modificarlos. El resultado es lo que el teórico denomina discurso, que va convertirse en lo que él define por "totalidad estructurada", esto es, el producto del discurso obtenido por la articulación entre fuerzas (o campos) hegemónicos distintos.

Es necesario aclarar que el uso de la categoría "totalidad estructurada" no es casual. Para Laclau, afirmar la existencia de un núcleo universal y estructurado sirve como base material, fondo y orientación ideológica. Sin esa unidad totalizadora y estructurada del discurso, todo su fundamento teórico se fragmentaría. Como manera de distinguirse del materialismo historicista y determinista del marxismo ortodoxo, Laclau rechaza la idea de totalidad histórica y reconoce frente al plan político contemporáneo la fragmentación de identidades. Pero al definir las estrategias de conquista de una hegemonía del discurso y afirmar la existencia de una re-totalización en cierto orden como horizonte - Laclau retoma el tema de la constitución de bloques históricos y de la posibilidad de reconstruir identidades colectivas.

El esfuerzo de Laclau por actualizar categorías y deshacerse de la exclusividad de las determinaciones del marxismo tradicional es en sí mismo pragmático, una vez que él intenta expandir el número de factores y elementos que interfieren sobre la lucha hegemónica (que suplanta, en cierta manera, la idea de lucha de clases cómo factor exclusivo de la revolución socialista). En su apropiación del socialismo como régimen, Laclau expande la concepción del término: más allá de la eliminación de la propiedad privada de los medios de producción, la lucha por el cambio de régimen por una sociedad basada en lo colectivo implica también otras formas de "liberación" que forman parte de diferentes campos hegemónicos. Lo que él denomina "totalidad de los ideales emancipatorios", no tiene ningún vínculo necesario y no se restringe a la lucha de clases. Se refiere, en este caso, a la multiplicidad de las causas por la cual la militancia democrática y socialista se dedica y compone las fuerzas hegemónicas en disputa. Laclau no deja de considerar la lucha por los derechos de las minorías como relevantes e importantes dentro del proceso histórico y del gran conjunto de batallas a que se dedica la política progresista (de izquierda) contemporánea, sino que las reafirma como parte de la lucha socialista de la contemporaneidad.

Al definir democracia como término ambiguo e inestable, como resultado de una multiplicidad de discursos hegemónicos que están construidos articuladamente, Laclau no 
encierra su teoría dentro de una trascendencia historicista utópica con ideales de perfección. La idea del marxismo como "fin último" y como resolución definitiva de los problemas sociales e históricos es para Laclau irrealista. Al asumir que ambigüedad e inestabilidad forman parte del proceso democrático, Laclau niega la idealización recurrente dentro del campo socialista que convierte el marxismo en valor dogmático. Lo moral y lo ético, que para Laclau están sostenidos por la multiplicidad, no determinan que la lucha de clases esté necesariamente unida a otras demandas, lo que de hecho nos deja espacio para pensar en la inmensidad de posibilidades políticas y de articulaciones pertinentes en el campo democrático como un todo. Al asumir la multiplicidad de identidades que forman el individuo, lo que hace el autor es evidenciar la gran dificultad de unificar un discurso progresista, valorizando la importancia del diálogo, de la negociación bajo el principio de articulación que él mismo define.

El en caso real de las elecciones del partido obrero (PT) en Brasil, es posible identificar mucho de lo que Laclau desarrolla como teoría en el ámbito práctico. Como podemos observar, la idea de bloques hegemónicos en disputa, asociados por articulaciones estratégicas inestables, configuró lo que fue el gran pacto político del partido de los trabajadores desde 2002. La idea del diálogo sugiere una negociación donde el peso de las decisiones políticas estaba y está determinado por el poder de cada una de las partes que componen la disputa. Si, por un lado, lo que la articulación política ofrece es la salida del impasse ideológico (los dos lados ceden a un propósito de interés compartido), por otro, queda una incongruencia inherente a la propia práctica. Laclau cree firmemente en el cambio de las partes en el proceso mismo de negociación, y postula la creación de una práctica compartida, donde cada lado responde a sus intereses. En ese caso, la idea de que puede haber un equilibrio de intereses en la negociación es sumamente problemática, pues no tiene en cuenta la asimetría que compone la disputa hegemónica, en otras palabras, los lados en disputa no son equivalentes. Como el propósito de la lucha hegemónica es la victoria, el movimiento de la lucha hegemónica es necesariamente desequilibrado. Así, la idea de negociación oculta el conflicto, que es lo que define la teoría marxista en su base filosófica. Según esta teoría, todo el proceso político está basado en el conflicto (de clase), en la lucha de intereses donde romper con el lado más fuerte, el capital, requiere de una violencia sistemática y definitiva: la toma del poder del proletariado. Aunque Laclau no termine con la noción del conflicto - de hecho la reafirma, al hablar de campos hegemónicos en constante disputa - su idea de la negociación como fin político deja un hueco sustancial: ¿cómo agregar fuerza y vencer a 
la disputa sin dejarse ser absorbido por las fuerzas hegemónicas preeminentes? ¿Cuáles son los límites (éticos, por ejemplo) de un partido en una negociación y concesión donde la lucha es necesariamente asimétrica? ¿Cuál sigue siendo el propósito de la lucha, si la articulación requiere el consenso de todas las partes?

En el caso preciso del PT, la victoria representó la negociación entre sectores diversos de la sociedad, con el fin de salir de las bases populares y congregar apoyo, añadiendo una parte del sector productivo (antes en visible decadencia económica), sin dejar de mantener un discurso dirigido a las clases populares. Si recordamos la llamada "Carta al Pueblo Brasileño", firmada por Lula en 2002, el candidato mencionaba su propósito fundamental en los cambios propuestos por el partido: crecer, incluir, pacificar. Cambiar para conquistar desarrollo económico y justicia social. Cambiar para evitar un colapso económico, social y moral. Lo mismo se percibe en la película documental: en Entreactos, Lula también deja claro los propósitos específicos del partido: hay que cambiar las relaciones entre Estado y sociedad mientras se gobierna.

El argumento principal que compuso la plataforma de gobierno del PT consistió en una reestructuración económica y social capaz de reorganizar las fuerzas productivas del país con un incremento en el mercado de consumo interno brasileño (así postulaba el PT toda su agenda desde 2002). Para esto, el esfuerzo significaría combinar desarrollo económico con la redistribución de renta como pilar central de la administración. Si para la izquierda entusiasmada las propuestas del PT fueron interpretadas como estrategias con el fin de obtener cambios radicales necesarios para la sociedad y la economía coherentes con la historia de este movimiento social - para la derecha conservadora, la llegada del PT al poder representaba una amenaza a su posición de clase siguiendo los principios de la retórica neoliberal. Una vez en marcha, el resultado de las acciones prácticas del gobierno no correspondió a ninguna de esas dos expectativas. El crecimiento de la economía combinado con la expansión sistemática de la clase media (incorporando sectores populares dentro de la categoría) no respondió ni a los cambios radicales exigidos por la izquierda ni a los pronósticos drásticos que indicaban la inestabilidad política y económica del país. Esa doble "decepción" que simbolizó el lugar del partido deja espacio para pensar la idea de la articulación propuesta por Laclau desde el punto de vista práctico. Combinar negociación y reformas, dentro del eje de un consenso significa definir prioridades, y crear un juego político capaz de legitimar y convertir los intereses de una parte en los intereses del todo. 
Por otro lado, Laclau ofrece una salida efectiva, al afirmar la multiplicidad de perfiles que configuran el sujeto político, sus intereses y su filiación a un proyecto político. Esta multiplicidad consiste en un conjunto de elementos que perfilan la definición de un partido, no solamente en su orientación económico-ideológica. Estar comprometido con el movimiento obrero no significa necesariamente compartir todas las ideas de un socialismo democrático. Tampoco significa rechazar la lucha por derechos y condiciones sociales más justas y dignas. $Y$ la posibilidad de que coexistan ambigüedades y contradicciones internas es precisamente lo que, según Laclau, define el carácter democrático de un grupo, sujeto político o partido (como en el ejemplo de Lula y el Partido de los Trabajadores).

Desde otro plano teórico, aunque referido a la práctica política, Alain Badiou se propone pensar la categoría ética en los discursos teóricos y políticos de la contemporaneidad. Comenzando por revisar las nociones de ética en teóricos como Kant y Lévinas, Badiou reconsidera los distintos niveles de trascendencia del principio de la moral que están ocultos en las ideas de tolerancia, alteridad y humanismo. A la llamada "ética de las diferencias", que sintetiza el argumento del uso de la tolerancia como principio, Badiou contesta de manera radical. Criticando a Lévinas, por ejemplo, Badiou afirma que el principio de devoción del Otro está necesariamente asegurado por una concepción mimética de duplicación del uno, lo cual es bastante problemático. La distancia que separa uno y otro en la relación de alteridad es aquella que permite a uno reconocer y disfrutar en el otro lo suyo propio. Para ser inteligible, según Badiou, la ética (que él critica) requiere que el Otro esté sostenido por un principio de alteridad que Lévinas denomina "altogether other", principio éste que trasciende la finitud de la experiencia. El Otro constituye una imagen determinada y fija, siempre remitida a su similitud y diferencia en relación a uno mismo. Por fin, el dominio de lo ético por una idea de alteridad resulta en un axioma religioso. La filosofía termina anulada por la teología, conforme afirma el teórico francés. Todo el esfuerzo por convertir la ética en un principio de pensamiento y acción es de por sí esencialmente religioso. Ese Otro pasa, por lo tanto, a ser celebrado en cuanto ente que es capaz de compartir los códigos de valores particulares aceptados social y políticamente como universales: los derechos de las mujeres, el ambientalismo (environmentalism) como conducta de la praxis, etc., son derechos naturalizados, se vuelven referencias comunes y definen cuándo el Otro es o no es "amistoso" o cuándo se convierte en un potencial "enemigo". Por fin, en la base de sustentación de la idea de los derechos humanos como principio categórico se invoca al 
respeto por las diferencias que en última instancia remiten a un punto común: la obediencia a una identidad universal - que es el objeto a que Badiou se opone.

A partir de ahí, Badiou empieza a construir las categorías que va utilizar para proponer una ética partiendo de la completa anulación de su principio moral y teológico. Contraponiéndose a las bases metafísicas, Badiou postula la experiencia como fundamento de la consistencia ética. Negando de manera categórica la existencia de Dios, para rechazar cualquier idea de origen y unicidad, él amplía el concepto de la ética mediado por múltiples diferencias, indefinidas e infinitas. Según este principio, existen tantas diferencias entre yo y yo mismo como entre un campesino sueco y un morador de las áreas urbanas pobres en China, por ejemplo.

El concepto de interés es crucial y debe de ser entendido como perseverancia (de y en el Ser), y no como el interés personal o material de uno en relación a un objeto o al conocimiento de manera específica. La ética para Badiou debe manifestarse como un "interés desinteresado", como una curiosidad que motiva fuerzas de perseverancia activamente. El "interés desinteresado" aparece aquí en un sentido radical, en la medida en que el objetivo es enlazar fuerzas en una fidelidad, que constituye el proceso de verdad, tal como lo define. Estas categorías son fundamentales y se articulan directamente con la idea de evento, que es el fundamento teórico de la ética que él plantea.

La idea de evento es definida por Badiou como un momento extra-ordinario capaz de extrapolar su circunstancia particular para alterar una situación dada. El evento forma parte de un movimiento marcadamente potencial, iniciado en vías de un cambio efectivo, proceso que Badiou llama fidelidad. La verdad es el resultado de ese proceso de fidelidad ocurrido dentro de un evento, su efecto dentro de la situación. Badiou considera al evento como un componente de ruptura, y la verdad que se materializa en la situación es inmanente y no se materializa sino ahí. No hay verdades reinantes, todo está dado y determinado por la acción del evento, por ese movimiento específico. La ruptura constituye una activación en donde se crea otro significado junto a un significante ya conocido, lo que Badiou denomina un proceso de verdad. Cuando pasamos a pensar en la situación a partir del evento, es porque hubo esa ruptura, y la fidelidad del evento se consolidó dentro de la situación. El evento, por fin, debe transformar la situación desde sus bases.

La existencia del evento está, por lo tanto, relacionada con la situación, con un dado vacío de significado. Tal como define Badiou, el evento está relacionado de manera 
suplementaria con una situación sin que esté necesariamente atado a sus reglas o a determinaciones categóricas. Lo que conecta al evento con su característica definidora es precisamente el vacío inherente a una situación previa al cambio que puede ocurrir. Badiou sintetiza: "the fundamental ontological characteristic of an event is to inscribe, to name, the situated void of that for which it is an event"4. Nombrar (to name) es la palabra clave que indica el aspecto consecuente o de resultado del evento relacionado con la situación.

Badiou parte de tales premisas para redefinir una ética exenta de cualquier referencia metafísica. Para él, concebir la ética significa anular todo y cualquier principio moral y teológico para construir una ontología de características distintas. La experiencia aparece como fundamento de consistencia ética, sin la existencia de Dios, sin principio genealógico (histórico) único. Evento y situación funcionan como ámbitos de actuación que definen la posibilidad del acontecer (ocurrence) de la verdad. En ellos es posible observar y calificar la existencia y la inmanencia de los procesos de verdad, que son lo que caracteriza a la ética. Considerando que el sujeto humano no tiene valor positivo o negativo per se, la emergencia de lo malo y de lo bueno dependerá precisamente de esa (rara) presencia real de los procesos de verdad en la situación.

El sujeto es el sostenedor de esa fidelidad, aquel que lleva el proceso de verdad. Por lo tanto, el sujeto no puede preceder a ese proceso, sino que él forma parte de esa construcción inmanente. En otras palabras: el sujeto no existe en la situación anterior al evento. Se podría afirmar que el proceso de verdad induce a la creación del sujeto. El sujeto de la revolución política no es el individuo militante, sino la producción singular que toma diferentes nombres (as veces partido, pero no exclusivamente). Así, la ética de los procesos de verdad (en plural) termina en el sentido opuesto al sentido kantiano de moralidad, pues no existe ética sin su referente directo. Tal como afirma Lacan, para Badiou la ética es necesariamente la de la política, la del amor, la de la ciencia y del arte. No existe, por tanto, un sólo sujeto de verdad, sino múltiples y están necesariamente referidos a una de esas cuatro categorías subrayadas por el pensador.

Al responder a algunos de los conceptos clave definidos por Badiou en Ethics, queda bastante claro que para Laclau es precisamente la idea del vacío y de la relación

\footnotetext{
${ }^{4}$ Badiou, Alain (2001). Ethics: an essay on the understanding of evil. Translated by Peter Hallward, London; New York: Verso, p. 69.
} 
entre evento y situación lo que constituye los aspectos problemáticos. La idea de un evento sin significado predefinido como disparador de un cambio efectivo y definitivo en una situación, sin que haya durante ese proceso una correspondencia o un "llenar" de significado, es lo que Laclau rechaza de manera sistemática a lo largo de su argumento teórico. Según Laclau: "el procedimiento de verdad en el que participan sus sujetos consiste, en una de sus dimensiones básicas, en la reconstitución de la situación en torno a un nuevo núcleo (77) ${ }^{\prime 5}$. La consecuencia - afirma - es que ya no es posible visualizar 0 entender las consecuencias del acontecimiento: "éste tiene que exhibir sus capacidades de articulación yendo más allá de sí mismo", lo que fuerza la separación entre vacío y el sitio del acontecimiento. Como resultado final, se vuelve necesaria cierta forma de llenar el vacío de manera especial, que requiere de una descripción teórica, de lo que carece el planteamiento del pensador francés. Todas las formas por la cual Badiou entiende ese llenar del vacío son, según Laclau, lo malo, lo que termina en una distinción fundamental: aun necesario e inevitable, el significado final del proceso de verdad tenderá a resultar en algo negativo para Badiou. En el polo opuesto, para Laclau, a través de una equivalencia (y de una trascendencia) de particularidades se puede construir algo como el nombre del vacío que ocupe la situación de manera definitiva, sin que eso signifique algo positivo o negativo.

¿De qué manera podríamos pensar la victoria del partido obrero en Brasil en 2002 a partir de estos términos?

Al definir el enfoque específico de su documental, João Moreira Salles - director y creador de Entreactos - anuncia sus objetivos: producir un documental de los momentos decisivos de la campaña electoral brasileña de 2002 con un énfasis en la figura del entonces candidato Luis Inácio Lula da Silva. Retratar a Lula, sin embargo, no es solamente delimitar su rol de candidato y su discurso, sino problematizar la relación entre el perfil social e individual del hombre y su telón de fondo: la ascensión del movimiento obrero en Brasil desde la década de 1970. Además de eso, la película añade complejidad al incorporar las escenas entre bastidores de la campaña, y mostrar las estrategias del partido en su intento de vencer las elecciones.

\footnotetext{
${ }^{5}$ El término habitus aquí se refiere al concepto de habitus desarrollado por Pierre Bourdieu, donde clasifica el conjunto de prácticas culturales que constituyen el perfil del individuo en su grupo social.

${ }^{6}$ En un dato momento de la película, Lula comenta el rol de los institutos de estadística social y llega a afirmar que deseaba recibir en su casa un representante del censo para hacerse notar que tenía sí un perfil socio económico de clase media.
} 
En una sola narrativa, la película es capaz de combinar la biografía de un personaje político de relevancia y su inserción dentro del proceso político en la contemporaneidad. Cuando Moreira Salles empieza el documental afirmando su interés por mostrar a Lula entre bastidores, su objetivo tampoco es inocente. Por un lado, Salles nos presenta la identidad del sujeto político mucho más compleja que aquella de mediador del discurso de su partido y nos ofrece la posibilidad de pensar en el potencial de cambio político a través de estrategias de negociación efectivas. Por otro, la película ofrece al espectador la confirmación de una retórica: la plataforma de gobierno es equivalente al discurso del candidato desde su intimidad. La historia del sujeto Lula está atada de alguna forma al plan de gobierno de su partido, lo que confiere legitimidad a sus argumentos. En un plano analítico, el director busca reconfigurar el perfil histórico de una parcela de la clase obrera que hoy forma parte de la clase media brasileña, con todas sus implicaciones políticas y contradicciones que puedan existir. Al presentarnos el contexto de afirmación histórica del PT, el documental reenfoca su objetivo principal: subrayar la toma del poder menos radical que reformista, exitosa precisamente por su pragmatismo.

En la medida en que la película personaliza la figura de Lula, lo que se quiere resaltar es esencialmente cómo su identidad de clase media se mezcla con un perfil de clase popular. Por ejemplo, la recurrencia a escenas en las que Lula afirma su identidad de clase media es explorada en la película de manera sistemática. La insistencia por llevar siempre un buen traje, la importancia de llevar corbatas apropiadas para la ocasión, las imágenes de un cierto "lujo burgués" de su apartamento son presentadas en la película no más a menudo que todas las escenas en que el propio Lula sugiere su pasado obrero, sus gustos y sus habitus ${ }^{7}$ populares. La sugerencia del candidato de que se ponga música popular en su coche, la simplicidad de la barbería que frecuenta, el recuerdo del pasado en la fábrica sin ninguna nostalgia ${ }^{8}$, añaden una riqueza en el perfil del político más allá de la simbología de la elite que suele asociarse al ejercicio del poder.

Desde el punto de vista de la retórica, Lula afirma que la singularidad de su partido es parte de su propio proceso de creación. Al final, él fue constituido por una clase obrera salida de las fábricas, inquieta en su función de proletariado para asumir cargos políticos (él incluso menciona los éxitos electorales del PT desde su momento de formación). La

\footnotetext{
${ }^{7}$ El término habitus aquí se refiere al concepto de habitus desarrollado por Pierre Bourdieu, donde clasifica el conjunto de prácticas culturales que constituyen el perfil del individuo en su grupo social.

${ }^{8}$ En un dato momento de la película, Lula comenta el rol de los institutos de estadística social y llega a afirmar que deseaba recibir en su casa un representante del censo para hacerse notar que tenía sí un perfil socio económico de clase media.
} 
idea es afirmar que, al contrario que los partidos de izquierda tradicionales, compuestos por intelectuales salidos de la pequeña burguesía e insertados dentro de la fábrica, el PT constituyó un ejemplo distinto: fueron los trabajadores quienes poco a poco pasaron a ocupar los cargos de poder desde su nivel regional hasta llegar a la victoria en las elecciones presidenciales. Sin embargo, esta afirmación y argumento planteado por Lula se debe precisamente a la estrategia fundamental del partido: salir de sus bases para congregar apoyo político. Aunque está pragmáticamente construido, todo este esfuerzo está sostenido por una absorción del PT al centro del poder. El documental no deja de subrayar el alto nivel de negociación, y refuerza la articulación política de Lula en las recurrentes imágenes de sus asesores y colaboradores que le instruyen, aconsejan y ofrecen la mayor parte del aparato argumentativo que sostiene Lula como candidato. Por fin, Lula es presentado como el "mejor preparado", el más competente para llevar a cabo los cambios administrativos, pero la base de apoyo de esa preparación está en la compleja red de articulación política que interconecta la personalidad y la participación popular de Lula con una parte de la intelectualidad de la izquierda brasileña, que también integran el partido. En ese caso, el PT, salido de la clase obrera, confirma su legitimidad mediante la presencia de todo un aparato intelectual de la burguesía que confiere eficacia (pragmática) al discurso y agrega poder a este campo hegemónico.

Es posible afirmar que la llegada de Lula a la presidencia tiene la simbología del evento de Badiou. Si aceptamos la idea sugerida por la película de que el PT encuentra en ese momento una oportunidad de ascensión dada por sus particularidades (su origen y su capacidad de lanzarse como un puente de una plataforma de gobierno realista aunque capaz de promover cambios), el uso del término evento, así como lo concibe Badiou, tiene sentido. La imagen de Lula, como símbolo principal de ese movimiento, nace de la materialización de ese proyecto supuestamente unido al principio de un proceso de verdad. Recordemos la enunciación categórica de Lula en la película: "Hoy en Brasil la única figura de dimensión nacional soy yo, porque tengo detrás de mí todo un movimiento". Podríamos pensar en ese sujeto - fruto de un movimiento obrero - como capaz de representar, nombrar los huecos de una situación, siguiendo los principios de Badiou.

No obstante, la idea de simultaneidad y de reforma, que son la base del discurso de Lula, inserta una relación temporal que aleja la posibilidad de pensar ese evento desde el punto de vista de Badiou, pues es precisamente la idea de simultaneidad la que Badiou no comparte. En su formulación conceptual, la relación entre evento y situación es de 
ruptura y sustitución, mientras que en el discurso de Lula, estamos hablando de cambios orgánicamente construidos, desde dentro del proceso político. Es esa propuesta de cambio la que permite que la negociación (y la articulación) y el consenso ocurran. Al final, según presenta la película, para llegar al poder y gobernar democráticamente es necesario dialogar, conciliar intereses, negociar y conseguir apoyo para poner en práctica acciones y cambios estructurales.

Si ponemos este ejemplo en diálogo con las postulaciones de Badiou, quedan también algunas cuestiones pertinentes. De cierta manera, el discurso político "desinteresado", cuyo interés debe ser orientado a un fin colectivo, a una idea trascendente, es incompatible con la idea de articulación y negociación. Si Laclau considera el diálogo como manera de consolidar el discurso y de cambiar en el ámbito práctico y efectivo la ideología marxista, Badiou tiende a aislar la idea del evento dentro de una trascendencia. Para Badiou, a pesar de que la experiencia sirva como fundamento de la consistencia ética y de que esta experiencia esté definida por una multiplicidad de diferencias, no existe lugar para el conflicto. La contradicción principal de la ontología sugerida por Badiou es que él reconoce la trascendencia que forma parte del discurso de las diferencias, y se opone a la obediencia a una identidad única universal, pero, sin haber espacio para el diálogo, sin haber un evento capaz de completar los huecos de una situación, todo está remitido a un vacío recurrente. Podríamos preguntar cómo las diferencias entre los sujetos pueden ser superadas a fin de encontrar un discurso colectivo eficaz y capaz de cambiar la situación. Si el evento surge del hueco dejado por la situación, está sustraído de ella, entonces no hay manera de cambiar la situación de manera activa, sino que hay una espera constante por un dado momento, donde el proceso de verdad suplante la realidad presente y la convierta en algo nuevo, sin identidad afirmada. Pero en todo este proceso, no hay control ni poder de decisión. Según el propio Badiou, la ética de las verdades sirve como principio de perseverancia y de resiliencia, que es lo que permite impedir a lo malo como efecto posible de los procesos de verdad. Resiliencia aquí entendida como resistencia, como tenacidad necesaria para evitar lo malo. Pero precisamente en la ética de las verdades, lo que Badiou omite es la posibilidad de crear lo bueno, o lo sustancialmente positivo ${ }^{9}$.

\footnotetext{
9 Para Badiou, la concepción de lo malo depende de tres elementos: el vacío de la situación, la incertidumbre de la fidelidad y el poder de la verdad al marcar y forzar el conocimiento. Con relación al vacío, lo malo (evil) es lo que convoca la plenitud de la situación, el refuerzo y no su vacío, su incoherencia, su falta. En ese caso, lo malo se nombra por simulacrum o terror. La traición (betrayal) es el fallo de continuidad de la fidelidad, la incapacidad del evento de inferir sobre la situación un cambio efectivo, la
} 
La candidatura de Lula y la historia de un movimiento social presentados en el documental hacen evidentes las naturales contradicciones e incongruencias de la teoría política pensada tanto por Laclau como por Badiou. Desde el ámbito de la práctica política, la idea de negociación vacía el significado histórico de los cambios pensados desde un partido, y no se considera lo que sería la resistencia o el principio básico de orientación ideológica de un partido surgido de un movimiento social obrero. ¿Qué compromiso con el trabajador se establece en la plataforma de gobierno de Lula que no esté en función del crecimiento económico y de la expansión de la economía? ¿Qué tipo de dependencia tiene ese compromiso social con los intereses del capital que son, a su vez, absolutamente antitéticos a los principios del socialismo? Asumiendo que el partido represente el ideal reformista, por otro lado, ¿qué tipo de negociación es posible dentro de una estructura social históricamente formada por la desigualdad?

Sin embargo, la inocencia del pensamiento de Badiou no tiene en cuenta las necesidades reales de la práctica política. El evento - si pudiéramos pensar en el caso del PT - como originado desde un hueco dejado por la situación, tendría sentido aquí, pero necesariamente correspondería a un contenido firme, a un movimiento político dirigido a llenar este hueco simbolizado por la ausencia de las clases populares en el ejercicio del poder ejecutivo.

Tanto Badiou como Laclau tienen en consideración la pluralidad y la fragmentación de las identidades y la imposibilidad de unificarlas en una totalización colectiva, marca del pensamiento político progresista de izquierdas en la actualidad. Ya sea al pensar la ética como capaz de reorientar las acciones prácticas de los sujetos (Laclau), o ya sea como para repensar el rol del militante y su responsabilidad frente un principio ontológico (Badiou), ambos parten de la complicada red de discursos que retoman el marxismo en la contemporaneidad.

La pregunta final sería: ¿cuáles son los límites éticos de la práctica política? La llamada "toma de poder" de un partido de bases proletarias no deja de subrayar la complejidad de esa pregunta. Sean las contradicciones y ambigüedades, sea la capacidad de generar diálogos múltiples, es precisamente la visibilidad de la política y su

\footnotetext{
interrupción de un proceso de verdad. Por fin, lo malo como desastre (disaster) ocurre cuando la identidad de la verdad se refiere a una idea de poder total, cuando la esencia de una verdad es afirmada. Estos tres movimientos caracterizan lo malo dentro del propio proceso de verdad y no constituyen una oposición, como proponen los principios de la moral teológica que afirma la verdad en confrontación en el polo opuesto a lo malo. Ver Ethics (op.cit.)
} 
transparencia más allá de lo real lo que reafirma la importancia de la teoría marxista, histórica y filosóficamente. 


\section{Referencias Bibliográficas}

Badiou, Alain (2001). Ethics: An Essay on the understanding of evil. Translated by Peter Hallward. London; New York: Verso.

Entreatos (2004). Direção: João Moreira Salles, Rio de Janeiro: Videofilmes.

Laclau, Ernesto (1986). Del Post-Marxismo al radicalismo democrático: entrevista a Ernesto Laclau. Materiales para el Debate Contemporáneo, Montevideo: CLAEH.

(2008). "Por una ética militante". In Debates y combates: por un nuevo horizonte de la política, Buenos Aires: Fondo de Cultura Económica, p. 67-106.

Laclau, Ernesto e Mouffe, Chantal (1989). Hegemony and socialist strategy: toward a radical democratic politics, London: Verso.

Silva, Luis Inácio Lula da (2002). Carta ao Povo Brasileiro, São Paulo. Disponível em: < http://www2.fpa.org.br/portal/modules/news/article.php?storyid=2324>. Acesso em: dez. 2009.

Recebido para publicação em dezembro de 2012.

Aprovado para publicação em fevereiro de 2013. 